\title{
Novos táxons em Acanthocinini neotropicais (Coleoptera, Cerambycidae, Lamiinae)
}

\author{
Marcela L. Monné1,2 \& Miguel A. Monné1,2
}

${ }^{1}$ Museu Nacional, Universidade Federal do Rio de Janeiro, Quinta da Boa Vista, São Cristóvão, 20940-040 Rio de Janeiro-RJ, Brasil. ${ }^{2}$ Bolsista do CNPq.

\begin{abstract}
New taxa in Neotropical Acanthocinini (Coleoptera, Cerambycidae, Lamiinae). New taxa described: Atelographus decoratus sp. nov. from Brazil (Espírito Santo), Pseudosparna boliviana sp. nov. from Bolivia (Santa Cruz), Georgeana gen. nov. type species Georgeana azurea sp. nov. from Brazil (Espírito Santo, Rio de Janeiro, São Paulo and Santa Catarina), Alloeomorphus gen. nov. type species, Alloeomorphus formosus sp. nov. from Brazil (Rondônia) and Bolivia (Santa Cruz), Longilepturges gen. nov. type species, Longilepturges bicolor sp. nov. from Brazil (Rondônia and Maranhão) and Longilepturges xantholineatus sp. nov. from Ecuador (Napo), Brazil (Rondônia) and Bolivia (Santa Cruz), Paratrichonius gen. nov. type species, Paratrichonius caesius sp. nov. from Brazil (Mato Grosso).
\end{abstract}

KEYWORDS. New genera; new species; taxonomy.

RESUMO. Novos táxons em Acanthocinini neotropicais (Coleoptera, Cerambycidae, Lamiinae). Novos táxons descritos: Atelographus decoratus sp. nov. do Brasil (Espírito Santo), Pseudosparna boliviana sp. nov. da Bolívia (Santa Cruz), Georgeana gen. nov. espécie-tipo Georgeana azurea sp. nov. do Brasil (Espírito Santo, Rio de Janeiro, São Paulo e Santa Catarina), Alloeomorphus gen. nov. espécie-tipo, Alloeomorphus formosus sp. nov. do Brasil (Rondônia) e Bolívia (Santa Cruz), Longilepturges gen. nov. espécietipo, Longilepturges bicolor, sp. nov. do Brasil (Rondônia e Maranhão) e Longilepturges xantholineatus sp. nov. do Equador (Napo), Brasil (Rondônia) e Bolívia (Santa Cruz), Paratrichonius gen. nov. espécie-tipo, Paratrichonius caesius sp. nov. do Brasil (Mato Grosso).

PALAVRAS-CHAVE. Novos gêneros; novas espécies; taxonomia.

Utilizando material recebido de diversas instituições e do Museu Nacional descrevemos quatro gêneros e sete espécies inéditas pertencentes à tribo Acanthocinini.

As abreviaturas utilizadas correspondem às seguintes instituições: ACMT, American Coleoptera Museum, Texas, Estados Unidos; MNKM, Museo Noel Kempff Mercado, Santa Cruz, Bolívia; MNRJ, Museu Nacional, Universidade Federal do Rio de Janeiro, Rio de Janeiro, Brasil; MZSP, Museu de Zoologia, Universidade de São Paulo, São Paulo, Brasil; USNM, National Museum of Natural History, Washington, Estados Unidos.

\section{Atelographus Melzer, 1927}

Atelographus Melzer, 1927: 578; Monné, 1975: 248 (revisão); 2005: 22 (cat.).

Espécie-tipo, Atelographus sexplagiatus Melzer, 1927, por monotipia.

O gênero conta com duas espécies distribuídas na Mata Atlântica: A. sexplagiatus Melzer, 1927 e A. susanae Monné, 1975.

\section{Atelographus decoratus sp. nov.}

(Fig. 1)

Etimologia. Latim, decoratus = adornado, belo, em decorrência da ornamentação elitral.
Macho. Tegumento preto. Pubescência predominantemente acinzentada. A pubescência preta recobre no pronoto três manchas arredondadas a cada lado do meio, aproximadas do bordo anterior e outras três próximas ao bordo posterior e nos élitros abundantes máculas arredondadas em toda a superfície. A pubescência branca reveste no pronoto mancha no ápice do tubérculo lateral e nos élitros larga faixa mediana com a margem posterior de contorno irregular, mácula em ziguezague próxima da margem no inicio do terço distal e mácula estreita anteapical.

As antenas alcançam as extremidades dos élitros no quinto distal do antenômero V. Protórax, nos lados, projetado medianamente, não tuberculado. Pronoto sem elevações, uma fileira de pontos grandes e profundos junto aos bordos anterior e posterior. Processo prosternal com largura aproximadamente igual a um terço da largura de uma procoxa; processo mesosternal tão largo quanto a largura de uma mesocoxa. Élitros com ápices obliquamente truncados. Pontos densos e profundos na metade basal, superficiais e esparsos na metade distal, cada ponto com grânulo pequeno situado no interior da margem anterior.

Último urotergito semicircularmente chanfrado; último urosternito truncado na extremidade.

Fêmea. As antenas atingem os ápices dos élitros na extremidade distal do antenômero VI; último urotergito arredondado no ápice; último urosternito truncado na extremidade. 
Dimensões, em mm, macho/fêmea. Comprimento total, 7,5-9,5/8,1-11,0; comprimento do protórax, 1,3-1,9/1,6-2,0; maior largura do protórax, 2,2-2,8/2,5-3,1; comprimento do élitro, 4,9-6,6/5,5-8,6; largura umeral, 3,0-3,6/3,0-4,2.

Material-tipo. Holótipo macho, BRASIL, Espírito Santo: Linhares, IX.1971, B. Silva col. (MNRJ). Parátipos, mesma localidade do holótipo, fêmea, XII.1965, A. Maller col., macho, X.1971, B. Silva col., macho X. 1973, B. Silva col., macho, XII.1973, B. Silva col. (Parque Sooretama), fêmea, X.1963, F. M. Oliveira col., 2 machos, 2 fêmeas, X-XI.1967, F. M. Oliveira col. Conceição da Barra (Pedro Canário), macho, XI.1976, E. dos Santos col. Rio Itapemirim, macho, 5.XII.1908, J. F. Zikán col. Todos no MNRJ.

Discussão. A. decoratus sp. nov. difere das duas espécies descritas no gênero pelo desenho elitral; pela pontuação densa e profunda na metade basal dos élitros, cada ponto com um pequeno grânulo situado na parede anterior; pelo processo prosternal que mede aproximadamente um terço da largura de uma procoxa. Em A. sexplagiatus Melzer, 1927, as áreas de pubescência branca são compactas e sem pontos; a pontuação da metade basal dos élitros é pequena e esparsa e o processo prosternal é tão largo quanto a largura de uma procoxa. Em cada élitro de $A$. susanae Monné, 1975 (Fig. 2) existem três áreas de pubescência branca, os pontos da metade basal dos élitros são desprovidos de grânulos e a largura do processo prosternal alcança pelo menos a metade de uma procoxa.

\section{Pseudosparna boliviana sp. nov.}

(Fig.3)

Etimologia. Boliviana, alusivo ao país onde os exemplares foram coletados.

Macho. Tegumento predominante castanho-escuro; metade basal do antenômero IV, coxas e metade anterior dos fêmures amarelados. Pubescência de maneira geral castanhoescura. A pubescência branco-acinzentada constitui faixa longitudinal a cada lado do pronoto, que se continua próxima às margens externas dos élitros até as extremidades.

As antenas atingem os ápices dos élitros no quarto basal do antenômero VI; escapo e antenômero III com pelos longos esparsos na face látero-ventral. Protórax com projeção lateral obtusa junto à margem anterior e tubérculos com ápice aguçado dirigido para trás, próximo ao bordo posterior. Élitros semicircularmente chanfrados na extremidade, ângulo externo projetado em espinho aguçado; pontos pequenos e superficiais em toda a superfície. Processo prosternal muito estreito, com um décimo da largura de uma procoxa; processo mesosternal com aproximadamente um quinto da largura de uma mesocoxa.Últimos urotergito e urosternito levemente chanfrados na extremidade distal.

Fêmea. As antenas alcançam os ápices dos élitros na metade anterior do antenômero VII; últimos urotergito e urosternito truncados.

Dimensões, em mm, macho/fêmea. Comprimento total, 5,0/ 5,7 ; comprimento do protórax, $0,8 / 1,0 ;$ maior largura do protórax, 1,1/1,2; comprimento do élitro, 3,7/4,1; largura umeral, 1,3/1,5.
Material-tipo. Holótipo macho, BOLÍVIA, Santa Cruz: Amboro, rd above Achira, 9-11.X.2004, Morris \& Wappes col. (MNKM). Parátipos, mesmos dados do holótipo, fêmea (MNRJ); Prov. Florida, Vicoquin area above Achira rd to Amboro, macho, 9-11.XI.2007, S. W. Lingafelter col. (USNM).

Discussão. Pseudosparna boliviana sp. nov. assemelhase a P. luteolineata Mermudes \& Monné, 2009, pela presença de manchas longitudinais de pubescência nos élitros, e dela se, separa pela coloração das manchas elitrais pela extensão do tegumento amarelado do antenômero IV, e pelas manchas elitrais branco-acinzentadas; , em P. luteolineata, as manchas elitrais são nitidamente amarelas e o tegumento amarelado ocupa os três quartos basais do antenômero IV.

\section{Georgeana gen. nov.}

Espécie-tipo. Georgeana azurea sp. nov.

Etimologia. Homenagem a Georgeana Mello pela sua inestimável amizade.

Corpo cilíndrico, pouco deprimido dorso-ventralmente. Olhos grosseiramente facetados; lobos superiores tão afastados entre si quanto três vezes a largura de um lobo; lobos inferiores duas vezes mais longos que as genas. Antenas com 11 antenômeros, pelo menos duas vezes mais longas que o corpo; escapo alongado, a extremidade distal atinge a base dos élitros; antenômero III apenas mais longo que o escapo, antenômeros IV-X gradativamente decrescentes para o ápice; antenômero XI mais curto que o X.

Protórax com tubérculo lateral proeminente, situado nos ângulos posteriores, ápice aguçado, parcialmente dirigido para trás. Pronoto liso; com uma fileira de pontos pequenos localizada junto ao bordo posterior. Processo prosternal plano, largura igual a um terço da largura de uma procoxa; processo mesosternal com metade da largura de uma mesocoxa. Élitros com setas eretas e abundante em toda a superfície, sem crista centro-basal e sem carenas; ápices retamente truncados.

Pernas relativamente curtas, sem setas eretas, fêmures levemente engrossados no terço apical; primeiro metatarsômero apenas mais longo que II+III.

Macho, com os últimos urostergito e urosternito truncados na extremidade distal. Fêmea, com curto ovipositor que apenas ultrapassa os ápices dos élitros; último urotergito truncado com leve entalhe triangular mediano na extremidade distal; último urosternito truncado no ápice.

Discussão. Georgeana gen. nov. pertence ao grupo de gêneros que envolve Trichonius Bates, 1864, Pentheochaetes Melzer, 1932, Piezochaerus Melzer, 1932 e Trichonyssodrys Gilmour, 1957, com o seguinte conjunto de caracteres: pêlos eretos em toda a superfície dos élitros; protórax com tubérculo lateral situado nos ângulos posteriores ou no terço posterior, pronoto sem tubérculos; élitros sem crista centro-basal e sem carenas, processo mesosternal com $1 / 3$ a metade da largura de uma mesocoxa e primeiro metarsômero apenas mais longo que II+III. Georgeana gen. nov. separa-se de Piezochaerus 

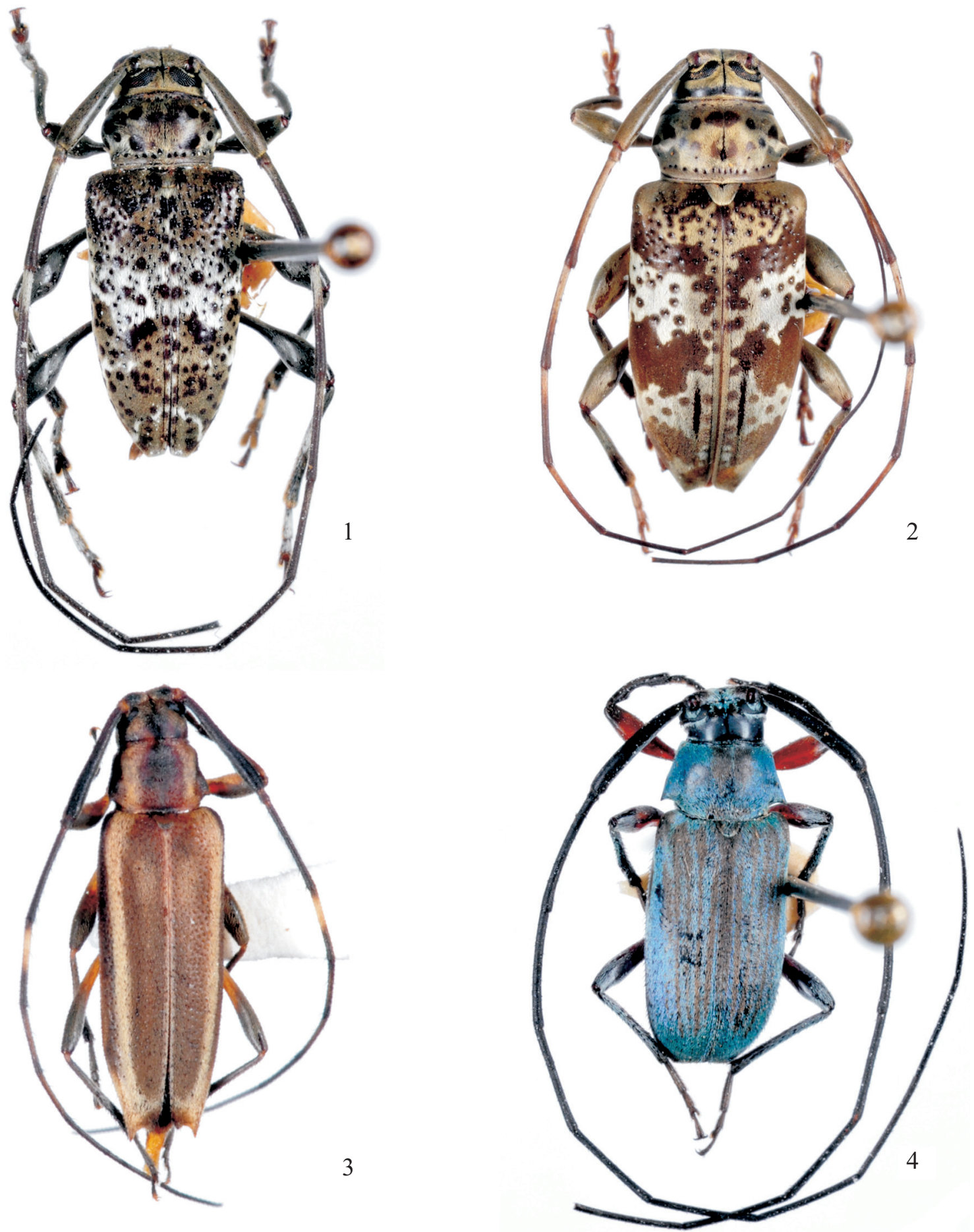

Figs. 1-4. 1. Atelographus decoratus sp. nov., holótipo macho; 2. Atelographus susanae Monné, macho; 3. Pseudosparna boliviana sp. nov., holótipo macho; 4. Georgeana azurea sp. nov., holótipo macho.

pelo corpo cilíndrico, pouco achatado dorso-ventralmente e pelo processo mesosternal com a metade da largura de uma mesocoxa; em Piezochaerus o corpo é fortemente deprimido dorso-ventralmente e o processo mesosternal alcança apenas um terço da largura de uma mesocoxa. Os tubérculos laterais do protórax em Pentheochaetes e Trichonyssodrys estão situados no início do terço posterior, em Georgeana gen. nov. os tubérculos coincidem com os ângulos posteriores. Georgeana gen. nov. separa-se de Trichonius pela ausência de pêlos eretos nas pernas e antenas e pelos tubérculos laterais do protórax aguçados, com o ápice parcialmente dirigido para trás, em Trichonius as antenas e pernas possuem abundantes pêlos eretos e os tubérculos laterais do protórax são rombos ou sem ápice aguçado e dirigidos para os lados. 


\section{Georgeana azurea sp. nov.}

(Fig. 4)

Etimologia. Persa. Azurea = azul, alusivo à coloração da pubescência predominante.

Macho. Tegumento predominantemente preto. Fêmures castanho-avermelhados, exceto o ápice, a metade dos médios e a base dos posteriores castanho-avermelhados. Pubescência de maneira geral azul-clara densa e compacta, com brilho metálico sob determinada incidência de luz. Cada élitro com 5 a 6 linhas longitudinais dorsais de pubescência cinzentoescura, paralelas entre si; as mais próximas da sutura, estendidas da base até o início do quarto distal. Antenas, pernas e abdome revestidos por fina e esparsa pubescência cinzenta.

As antenas alcançam os ápices dos élitros no meio do antenômero V. Pronoto liso, com apenas uma fileira de pontos pequenos junto à margem posterior. Élitros transversalmente truncados, muito fina e esparsamente pontuados em toda a superfície.

Fêmea. As antenas alcançam as extremidades dos élitros no ápice do antenômero $\mathrm{V}$.

Dimensões, em mm, macho/fêmea. Comprimento total, 5,6-6,0/7,2-8,4; comprimento do protórax, 1,1-1,2/1,4-1,6; maior largura do protórax, 1,6-1,9/2,1-2,5; comprimento do élitro, 3,8-4,2/5.0-5,6; largura umeral, 4,9-6.6/2,3-2,9.

Material-tipo. Holótipo macho, BRASIL, Espírito Santo: Conceição da Barra (Pedro Canário), X.1972, Oliveira \& Roppa col. (MNRJ). Parátipos: mesmos dados do holótipo, macho. Rio de Janeiro: Rio de Janeiro (Corcovado), fêmea, 30.IX.1955, D. Zajciw col; mesma localidade e coletor, fêmea, 24.XI.1956; macho, 19.X.1957; mesma localidade, macho, 25.X.1957, Seabra \& Alvarenga col.; mesma localidade e coletores, macho, 14.XI.1958; macho, 30.IX.1959; fêmea, 18.X.1959; macho, 5.XI.1962; duas fêmeas, 31.X.1967; macho, X.1968, S. A. Fragoso col; fêmea, XI.1971, Seabra \& Alvarenga col; macho, XI.1972, Seabra \& Alvarenga col.; macho, 25.X.1974, M. A. Monné col. (Represa Rio Grande), macho, I.1963, F. M. Oliveira col. São Paulo: Peruibe, macho, 4.II.1941, H. Zellibor col. Santa Catarina: Hansa Humboldt [Corupá], macho, XI.1932, A. Maller col. Todos no MNRJ.

Variabilidade. A coloração azul da pubescência predominante varia de intensidade e de brilho metálico de acordo com as localidades. Os exemplares de Espírito Santo são intensamente azuis, nos do Rio de Janeiro a pubescência se torna azul-acinzentada, e as linhas dos élitros de pubescência cinzento-escura são mais largas e aproximadas entre si. Por fim, os exemplares de São Paulo e Santa Catarina são de pubescência cinzento-clara, uniforme, quase sem vestígios de azul ou cinzento-escura.

\section{Alloeomorphus gen. nov.}

Espécie-tipo. Alloeomorphus formosus sp. nov.

Etimologia. Grego, alloeo $=$ diferente + morphus $=$ forma, aspecto.
Olhos grosseiramente facetados; lobos superiores tão afastados entre si quanto a largura de um lobo; lobos inferiores muito desenvolvidos, deixando apenas estreito friso genal. Antenas longas, pelo menos uma vez e meia mais longas que o corpo, filiformes, com 11 antenômeros. Escapo longo, o ápice alcança a base dos élitros, antenômero III levemente mais longo que o escapo ou que o IV, antenômeros V-XI subiguais em comprimento; face látero-ventral dos antenômeros III-IV com escassas setas curtas.

Protórax com tubérculo lateral muito desenvolvido, situado pouco atrás do meio, aguçado na extremidade e com o ápice voltado para trás. Pronoto liso, sem fileiras de pontos junto às orlas anterior ou posterior. Processo prosternal estreito, largura aproximadamente igual a um terço da largura de uma procoxa. Processo mesosternal muito estreito, com ligeira declividade na margem anterior, largura igual a um quarto da largura de uma mesocoxa.

Escutelo pequeno, arredondado no ápice. Élitros sem setas eretas, sem crista centro-basal e sem carenas; achatados dorso-ventralmente, margens paralelas e ápices arredondados. Pernas longas, pro- e mesofêmures levemente engrossados no meio, metafêmures lineares. Tíbias lineares; primeiro metatarsômero apenas mais longo que II+III

Macho com último urotergito arredondado no ápice; último urosternito truncado na extremidade distal; urosternitos I-IV com manchas semicirculares laterais de pubescência prateada.

Discussão. Alloeomorphus gen. nov. pelo conjunto de caracteres e pela coloração peculiar para a tribo Acanthocinini não pode ser comparado com nenhum outro gênero. A coloração lembra Acabyra aruama Martins \& Napp, 2006 (Cerambycinae, Pteroplatini) principalmente pelas linhas longitudinais dorsais de pubescência preta nos élitros.

\section{Alloeomorphus formosus sp. nov.}

$$
\text { (Fig. 5) }
$$

Etimologia. Latim, formosus belo, formoso, referente ao aspecto e coloração.

Macho. Tegumento predominantemente preto; tegumento amarelado nos antenômeros VII-XI e no terço basal dos élitros; tegumento castanho-ferrugíneo nos dois terços basais do escapo e faixa transversal junto à margem posterior do pronoto. A pubescência castanho-escura recobre a cabeça, o terço apical do escapo, os antenômeros II-VI, pernas e face ventral. Terço anterior dos élitros revestidos por pubescência amarelo-dourada, os dois terços posteriores revestidos de pubescência cinzenta com brilho prateado, a pubescência preta recobre as margens laterais e duas linhas dorsais longitudinais subparalelas que não alcançam os ápices.

As antenas atingem os ápices dos élitros no terço distal do antenômero V. Pronoto sem pontuação visível (50x). Élitros muito finamente pontuados no terço basal, nos dois terços apicais com pontos maiores, parcialmente alinhados dispostos nas faixas dorsais recobertas por pubescência preta.

Dimensões, em mm, holótipo macho. Comprimento total, 5,9; comprimento do protórax, 1,1; maior largura do protórax, 
1,8; comprimento do élitro, 4,0; largura umeral, 2,0.

Material-tipo. Holótipo macho, BRASIL, Rondônia: Ouro Preto do Oeste, X.1986, O. Roppa, P. Magno \& J. Becker col. (MNRJ). Parátipos, BOLÍVIA, Santa Cruz: 4-6 km SSE Buena Vista (Hotel Flora \& Fauna), macho, 16-30.XI.2002, R. Clarke col. (ACMT); mesma procedência e coletor, fêmea, 7.X.2004 (ACMT); Reserva Natural Potrerillo del Guenda (400 m), macho, 16-21.X.2006, Nearns \& Wappes col. (ACMT).

\section{Longilepturges gen. nov.}

Espécie-tipo. Longilepturges bicolor sp. nov.

Etimologia. Latim, longi $=$ alongado + Lepturges, gênero de Acanthocinini.

Olhos finamente facetados; lobos superiores tão afastados entre si quanto duas vezes a largura de um lobo; lobos inferiores subiguais às genas. Antenas longas, aproximadamente duas vezes o comprimento do corpo, filiformes, com 11 antenômeros. Escapo longo, o ápice alcança a margem posterior do protórax, antenômero III com comprimento subigual ao escapo, antenômeros IV-X subiguais em comprimento; antenômero XI aproximadamente uma vez e meia o comprimento do X; face látero-ventral dos antenômeros III-IV com escassas setas curtas.

Protórax com tubérculo lateral desenvolvido, situado nos ângulos posteriores, aguçado na extremidade e com o ápice ligeiramente voltado para trás. Pronoto liso, com uma fileira de pontos junto á margem posterior em Longilepturges bicolor (fileira de pontos ausente em L. xantholineatus). Processo prosternal estreito, largura aproximadamente igual a um quinto da largura de uma procoxa. Processo mesosternal muito estreito, com ligeira declividade na margem anterior, largura aproximadamente igual a um quarto da largura de uma mesocoxa.

Escutelo pequeno, arredondado no ápice. Élitros alongados com comprimento pelo menos três vezes a largura umeral, sem setas eretas, sem crista centro-basal e sem carenas, margens paralelas e ápices obliquamente truncados. Pernas moderadamente longas, fêmures engrossados no meio, metafêmures lineares. Primeiro metatarsômero mais de duas vezes mais longo que II+III.

Discussão. Longilepturges gen. nov. pertence ao grupo de gêneros com os caracteres: élitros sem setas, sem carenas e sem crista centro-basal, antenas filiformes, protórax com tubérculos laterais desenvolvidos, coincidentes com os ângulos posteriores. O grupo de gêneros está integrado por Lepturgantes Gilmour 1957, Paroecus Bates, 1863, Pattalinus Bates, 1881 e Lepturges Bates, 1863. Em Lepturgantes as antenas tem 12 antenômeros e as antenas dos machos de Paroecus e Pattalinus apresentam espinho ápico-interno nos antenômeros V ou VI. Longilepturges gen. nov. têm 11 antenômeros e nos machos são desprovidas de espinho. O gênero mais próximo é Lepturges do qual se separa pelos élitros alongados com comprimento pelo menos três vezes a largura umeral, em Lepturges o comprimento dos élitros, no máximo, alcança uma vez e meia a duas vezes a largura umeral.

\section{Chave para as espécies de Longilepturges gen. nov.}

Cabeça e protórax uniformemente alaranjados, élitros revestidos com pubescência cinzento-acastanhada Brasil (Rondônia e Maranhão) ......Longilepturges bicolor sp. nov.

Cabeça e protórax castanho-escuros; élitros castanho-escuros com linhas longitudinais de pubescência amareloacinzentada. Brasil (Rondônia), Equador (Napo), Bolívia (Santa Cruz) ....... Longilepturges xantholineatus sp. nov.

\section{Longilepturges bicolor sp. nov.}

(Fig. 6)

Etimologia. Latim, bicolor $=$ duas cores, referente as cores do tegumento.

Macho. Tegumento predominantemente preto; alaranjado na cabeça e protórax. Pubescência de maneira geral cinzentoacastanhada. Em cada élitro duas linhas longitudinais estreitas de pubescência preta, a interna paralela e aproximada da sutura, da base ao início do quarto apical; a externa, junto à margem, expandida, recobrindo o ápice do élitro.

As antenas alcançam os ápices dos élitros no meio do antenômero VI. Pronoto com uma fileira de pontos junto ao bordo posterior. Élitros obliquamente chanfrados na extremidade; superfície finamente pontuada nos três quartos anteriores. Últimos urotergito e urosternito truncados no ápice.

Fêmea. As antenas atingem os ápices dos élitros no meio do antenômero VII; último urotergito arredondado no ápice; último urosternito truncado na extremidade distal.

Dimensões, em mm, macho/fêmea. Comprimento total, 9,0-9,9/8,8; comprimento do protórax, 1,5-1,8/1,5; maior largura do protórax, 1,8-2,2/1,8; comprimento do élitro, 6,46,8/6,3; largura umeral, 2,0-2,3/2,0.

Material-tipo. Holótipo macho, BRASIL, Rondônia: Ouro Preto do Oeste, X.1986, O. Roppa, P. Magno \& J. Becker col. (MNRJ). Parátipos: mesmos dados do holótipo, 2 machos. Rondônia: Ariquemes, fêmea, IX.1983, B. Silva col. Maranhão: Imperatriz (Horto Florestal Arara Azul), macho, X.2001, L. F. Reys col. Todos no MNRJ.

\section{Longilepturges xantholineatus sp. nov.} (Fig. 7)

Etimologia. Grego, xantho = amarelo + lineatus = linha, faixa, alusivo à coloração das manchas de pubescência dos élitros.

Macho. Tegumento predominantemente castanho-escuro; castanho-avermelhado no escapo e nas margens externas dos élitros. Pubescência de maneira geral castanho-escura. Com pubescência amarelo-acinzentada na fronte e em faixa longitudinal larga entre os lobos superiores dos olhos; no pronoto em uma faixa mediana longitudinal de lados paralelos e uma mancha alongada nas margens externas; nos élitros em três faixas longitudinais, duas na metade basal, a interna paralela e aproximada da sutura, mais longa que a externa e a terceira suboblíqua no dorso do terço apical. 

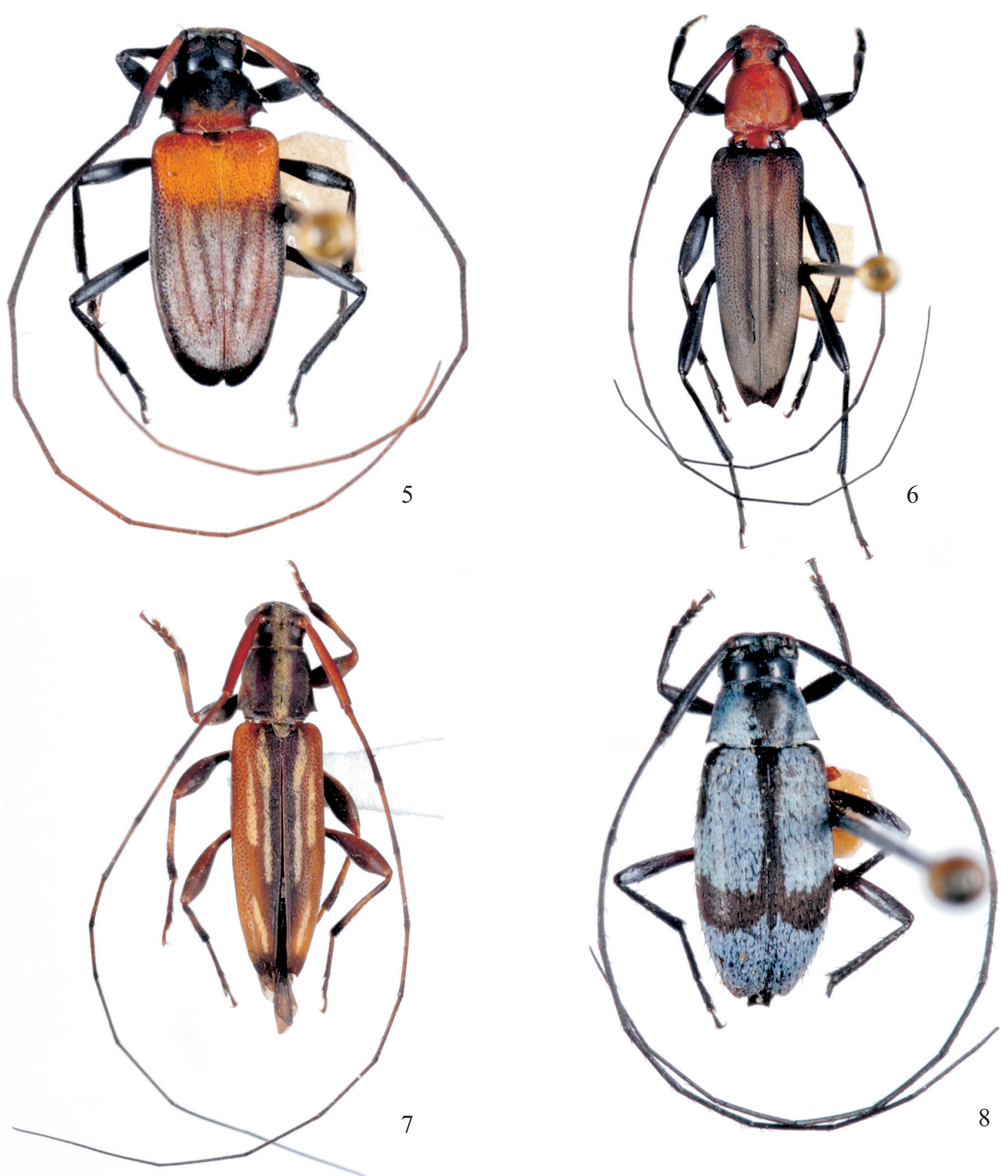

Figs. 5-8. 5. Alloeomorphus formosus sp. nov., holótipo macho; 6. Longilepturges bicolor sp. nov., holótipo macho; 7. Longilepturges xantholineatus sp. nov., holótipo macho; 8. Paratrichonius caesius sp. nov., holótipo macho.

As antenas atingem os ápices dos élitros aproximadamente no terço distal do antenômero VI; antenômero XI uma vez e um terço mais longo que o X. Pronoto com pontuação restrita a uma fileira de pontos pequenos junto ao bordo posterior. Élitros obliquamente chanfrados; ângulo externo projetado em dente aguçado. Pontuação pequena, moderadamente densa, concentrada nos lados da sutura. Últimos urotergito e urosternito truncados na extremidade distal.

Fêmea. Antenômero XI do mesmo comprimento que o X; últimos urotegito e urosternito arredondados na extremidade distal.

Dimensões, em mm, macho/fêmea. Comprimento total, 5,4-7,0/5,3; comprimento do protórax, 1,0-1,3/1,8; maior largura do protórax, 1,1-1,5/1,2; comprimento do élitro, 3,84,3/3,8; largura umeral, 1,2-1,6/1,3.

Material-tipo. Holótipo macho, BRASIL, Rondônia: Ariquemes, IX.1983, B. Silva col. (MNRJ). Parátipos: Rondônia: Ouro Preto do Oeste, macho, fêmea, X-XI.1983, O. Roppa, J. Becker \& B. Silva col. (MNRJ); mesma localidade, 2 machos, X.1986, O. Roppa, P. Magno \& J. 
Becker col. (MNRJ). EQUADOR, Napo: Lago Agrio, macho, IX.X.1977, J. Escobar col. (MNRJ). BOLÍVIA, Santa Cruz: El Cairo (5 km W Buena Vista), fêmea, 7.V.2004, Wappes \& Cline col. (ACMT); Prov. Florida (4 km N Bermejo, Refúgio Los Volcanes, 1045 m), macho, 1922.I.2007, Lingafelter, Wappes \& Prena col. (ACMT).

\section{Paratrichonius gen. nov.}

Espécie-tipo, Paratrichonius caesius sp. nov.

Etimologia. Grego, para = próximo + Trichonius $=$ gênero de Acanthocinini.

Corpo subcilíndrico, pouco deprimido dorso-ventralmente. Olhos grosseiramente facetados; lobos superiores estreitos, tão afastados entre si quanto quatro vezes a largura máxima de um lobo; ligação entre os lobos superiores e o inferior reduzida a duas fileiras de omatídios. Lobos inferiores com altura igual a uma vez e meia a altura das genas. Antenas com 11 antenômeros, mais de duas vezes o comprimento do corpo. Escapo alongado, a extremidade distal alcança a base dos élitros; antenômero III aproximadamente do comprimento do escapo, antenômeros IIIX gradativamente decrescentes para a extremidade, antenômero XI um terço mais longo que o X. Pêlos curtos eretos e esparsos em toda a superfície dos antenômeros.

Protórax com tubérculo lateral muito desenvolvido, coincidente com os ângulos posteriores, ápices fortemente aguçados, a extremidade parcialmente dirigida para trás. Pronoto liso, com uma fileira de pontos pequenos junto à margem posterior. Élitros com abundantes pêlos eretos em toda a superfície; ápices obliquamente truncados, ângulos sem projeções. Processo prosternal estreito, largura aproximadamente igual a um quinto da largura de uma procoxa; processo mesosternal com um terço da largura de uma mesocoxa. Pernas longas, as posteriores as mais desenvolvidas, com pêlos rígidos eretos em toda a superfície; fêmures lineares; primeiro metatarsômero uma vez e meia mais longo que II+III.

Macho, últimos urotergito e urosternito truncados na extremidade distal. Fêmea, ovipositor levemente projetado além dos ápices dos élitros; último urotergito arredondado no ápice; último urosternito semicircularmente chanfrado, ângulos projetados em curto espinho aguçado.

Discussão. O conjunto de caracteres que assemelham Trichonius, Georgeana gen. nov. e Paratrichonius gen. nov. são: antenas longas, filiformes, protórax com tubérculo lateral desenvolvido, coincidente com os ângulos posteriores, pronoto sem tubérculos, élitros com pêlos eretos, sem crista centrobasal e sem carenas. Paratrichonius gen. nov. separa-se de Georgeana gen. nov. pela presença de pelos eretos nas pernas e antenas, ausentes em Georgeana gen. nov. Em Trichonius antenas e pernas possuem abundantes pelos eretos, contudo os tubérculos laterais do protórax são rombos ou sem ápice aguçado e dirigidos para os lados; em Paratrichonius gen. nov. os tubérculos laterais do protórax são muito desenvolvidos, aguçados na extremidade e parcialmente dirigidos para trás.

\section{Paratrichonius caesius sp. nov.}

(Fig. 8)

Etimologia. Latim, caesius $=$ azul-acinzentado, referente à coloração da pubescência predominante.

Macho. Tegumento uniformemente preto. Pubescência de maneira geral azul-acinzentada, mais densa nos élitros. Nestes, pubescência preta em uma faixa que vai do escutelo até o terço posterior, de onde parte até os bordos de cada élitro; outra faixa, em cada élitro, a partir do úmero, junto ao bordo, até o terço anterior.

As antenas alcançam os ápices dos élitros no meio do antenômero V. Pronoto liso, com apenas uma fileira de pontos pequenos junto à margem posterior. Élitros com pontos setígeros densos e abundantes em toda a superfície, dispostos em fileiras longitudinais nos três quartos basais.

Fêmea. As antenas alcançam as extremidades dos élitros no ápice do antenômero $\mathrm{V}$.

Dimensões, em mm, macho/fêmea. Comprimento total, 4,7-4,9/5,4; comprimento do protórax, 1,0-1,0/1,0; maior largura do protórax, 1,5-1,5/1,7; comprimento do élitro, 3,33,6/3,9; largura umeral, 1,6-1,7/1,5.

Material-tipo. Holótipo macho, BRASIL, Mato Grosso: Sinop, (350 m), X.1976, Roppa \& Alvarenga col. (MNRJ). Parátipos, mesmos dados do holótipo 4 machos, 3 fêmeas (MNRJ); Barra do Tapirapé, macho, XI.1964, B. Malkin col. (MZSP).

Discussão. A extensão da pubescência preta elitral varia entre os exemplares, sofrendo intensa redução o que torna a superfície elitral quase totalmente azul-acinzentada, permanecendo apenas em linhas longitudinais circundando os pontos setígeros.

\section{AGRADECIMENTOS}

Agradecemos a Steve W. Lingafelter (USNM) e James Wappes (ACMT) pelo envio de material para estudo.

\section{REFERÊNCIAS}

Melzer, J. 1927. Longicórneos (Col.) do Brasil, novos ou pouco conhecidos. Revista do Museu Paulista 15: 557-582.

Monné, M. A. 1975. Contribuição ao conhecimento dos Acanthocinini. IV (Coleoptera, Cerambycidae, Lamiinae). Revista Brasileira de Biologia 35: 245-252.

Monné, M. A. 2005. Catalogue of the Cerambycidae (Coleoptera) of the Neotropical Region. Part II. Subfamily Lamiinae. Zootaxa 1023: 1-759.

Recebido 3/8/2010; aceito 14/4/2011

Editor: Lúcia Massutti de Almeida 